\title{
AGGREGATIONS OF MALLOS AND DICTYNA (ARANEAE, DICTYNIDAE): POPULATION CHARACTERISTICS
}

\author{
BY ROBERT R. JACKSON ${ }^{1}$ AND SANDRA E. SMITH \\ North Carolina Division of Mental Health Services \\ Research Section \\ P.O. Box 7532 \\ Raleigh, North Carolina 27611
}

\section{INTRODUCTION}

Generally web spiders are solitary animals. Usually only a single spider occupies a single web, with the relatively common exception of webs jointly occupied by a male-female pair or females with their young. In most species, occupied webs are usually not connected to other occupied webs by silk lines. However, aggregations of various types and degrees occur in some species (reviewed by Buskirk, 1975; Krafft, 1970; and Shear, 1970). These include cases in which occupied webs are in close proximity (sometimes touching), but occupied by single spiders, as well as cases in which single webs are occupied by groups of spiders of all sex/age classes. The species involved are sometimes referred to as "social spiders" (e.g., Burgess, 1978; Kullmann, 1972). At present relatively little is known about the social adaptations of these spiders. Some of the first things we would like to know about animals that occur in aggregations are the size, composition and spacing characteristics of naturally occurring groups. Data concerning these basic social characteristics will be presented in this paper for several species of dictynid spiders.

The Dictynidae are a group of web-building cribellate spiders, most of which have body lengths less than $5 \mathrm{~mm}$. In the closely related genera Mallos and Dictyna, there are species with different types of social organization. Most are solitary; at least three are communal, territorial; and at least one is communal, non-territorial. Each individual web of a solitary species consists of a mesh in which prey is captured and a nest within the mesh. Communal, territorial

\footnotetext{
${ }^{1}$ Present address:

Department of Zoology, University of Canterbury, Christchurch 1, New Zealand. Manuscript received by the editor June 10, 1978.
} 
species (M. trivittatus Banks, Dictyna calcarata Banks, D. albopilosa Franganillo) live in web complexes. Web complexes consist of variable numbers of web units, each consisting of a nest and a mesh; and web units are connected to each other by strands of silk in the interstitial web. Evidently, web units are treated by the occupants as defended territories (Jackson, 1978a). In the communal, nonterritorial species ( $M$. gregalis Simon), groups of spiders live in communal webs which consist of surface sheets with holes leading into the interior. The interior contains nests, tunnels and supporting lines connecting the sheet with the substrate beneath (see Burgess, 1976; Diguet, 1909a, 1915). Communal webs are not divided into defended units as in web complexes. More detailed information concerning social organization, web characteristics, and habitats is provided elsewhere (Jackson, 1978a).

\section{METHODS}

\section{DATA FROM NATURAL POPULATIONS}

For census areas, locations were chosen which seemed to have particularly high densities of spiders. The census areas for Mallos niveus O. P. Cambridge were one-dimensional (horizontal lines). All other census areas were rectangular. For D. calcarata and Censuses 3-6 for $M$. trivittatus, complete web complexes of relatively small size were used; and the boundaries of the census areas were chosen to closely correspond to the edges of the web complexes. The distance from each spider in the complex to the nearest conspecific in the vicinity but not in the complex was greater than twice the diameter of the complex in each of these census areas. For Census No. 1 and 2 for $M$. trivittatus, each area censused was part of a large web complex.

The corners of each census area were marked with pieces of tape. Each web or web unit was completely searched, a process that destroyed the web unit. The occupants of the units were recorded; and a piece of tape, with a code number, was placed at the location of each occupied nest before it was destroyed. The distance of each of these nests to its nearest neighboring nest was measured.

The exact locations of spiders on the sheet and interstitial webs proved excessively difficult to measure accurately. This was because they were frequently obscured from view by silk and debris; and the process of locating spiders inevitably disturbed them, leading to 
changes in their positions before they could be recorded. Only the component of the web (nest, mesh, interstitial web) occupied by the spider could be recorded with confidence. When counting the number of spiders per web unit, those in the interstitial web were included in the record of the web unit to which they were in closest proximity.

Spacing and density data were not collected for D. albopilosa. The web complexes of this species were particularly difficult to disassemble in the field because they were three-dimensional and located on the leaves, stems and roots in dense growths of herbaceous plants. Those of $D$. calcarata and $M$. trivittatus, in contrast, were two-dimensional and usually built on more accessible flat surfaces.

At San Anton Falls (Morelos, Mexico), 23 occupied web units of D. albopilosa were searched, and the occupants were recorded, with no attempt to assess density or spatial relations. In addition to the spiders in the census areas, the occupants of another 48 web units of $D$. calcarata and 152 of $M$. trivittatus were recorded. Each of these was in the general vicinity of the census areas.

Data for $M$. trivittatus were collected in June; those for $M$. niveus, D. calcarata, and D. albopilosa were collected in September. These species seem to feed predominantly in the late afternoon and early evening (Jackson, 1977a). Data in this study were collected at mid-day, when the spiders were less active.

\section{LABORATORY STUDIES - Mallos gregalis}

In the laboratory, $M$. gregalis in large communal webs were maintained on a diet of houseflies (Musca domestica), provided at approximately 5-day intervals. Temperature was maintained at approximately $24^{\circ} \mathrm{C}$, and the light cycle was approximately $13 \mathrm{~L}$ : 11D. These large colonies were begun from fewer than 200 spiders collected by Burgess (see Burgess, 1976) in Guadalajara, Mexico, 3 yr previous. The webs in the laboratory were on plants and other objects, and they were not enclosed.

Two census methods were used. 1. Small discrete communal webs and relatively discrete portions of larger communal webs were completely disassembled in the spring and early summer. All occupants were recorded; and the condition, structure, and size of the webs were recorded. 2. The surface of a large communal web, at least 2 years old, was censused with $30 \mathrm{~cm}$ transects in the fall. Each transect consisted of a string laid haphazardly onto the web, and all 
spiders within $1 \mathrm{~mm}$ of the string were counted. The web was arbitrarily divided into 3 sections. Two transects were placed onto each section on each census-day; and there were 11 census days, each 2 to 3 days apart. A "census" was defined as the sum of the spiders found on the two transects on a given section on a given census-day.

\section{Census Areas}

Mallos niveus

Three aggregations of $M$. niveus were censused in Guanajaato (Guanajaato, Mexico), each under a different window sill on exterior walls of buildings in the city. The webs were arranged in horizontal straight lines, and the length of the aggregation was defined as the distance between the first web at one end and the last web at the other end (Census Area No. 1, $54 \mathrm{~cm}$; No. 2, $87 \mathrm{~cm}$; No. $3,273 \mathrm{~cm})$. The distance to the nearest conspecific not in the aggregation was greater than length of the aggregation in each case.

\section{Mallos trivittatus}

Census Areas Nos. 1, 2, and 3 were at East Turkey Creek in the Chiracahua Mountains (Arizona, USA). The creek passes through a $1.8 \mathrm{~m}$ diameter metal culvert, with an interior surface area of $88 \mathrm{~m}^{2}$. Almost the entire interior of the culvert was covered by a single enormous web complex. The bottom of the culvert was covered by water; and in the immediate vicinity of the water, web units were scarce. Subtracting these parts of the culvert, the web complex was conservatively estimated to be $79 \mathrm{~m}^{2}$ in area. Census Areas Nos. 1 and 2 were each inside the culvert, within $2 \mathrm{~m}$ of opposite entrances and $1.5 \mathrm{~m}$ above the bottom of the culvert. Census Area No. 1 was $56 \mathrm{~cm} \times 50 \mathrm{~cm}$; No. $2,60 \mathrm{~cm} \times 56 \mathrm{~cm}$. Census Area No. 3 was a web complex $(54 \mathrm{~cm} \times 42 \mathrm{~cm}) 30 \mathrm{~m}$ from the culvert, on a large boulder (ca. $2 \mathrm{~m}$ high) beside the creek. The boulder was overhanging the ground, forming a shallow cave (ca. $1 \mathrm{~m}$ from ground to top; $0.5 \mathrm{~m}$ from entrance to back). The web complex was on the upper surface of the cave.

Census Area No. $4(56 \mathrm{~cm} \times 32 \mathrm{~cm})$ and No. $5(56 \mathrm{~cm} \times 56 \mathrm{~cm})$ were web complexes on rock ledges near Estes Park (Colorado, USA). Each was 1 to $2 \mathrm{~m}$ above the ground. Census Area No. 6 was a web complex $(124 \mathrm{~cm} \times 34 \mathrm{~cm})$ on the upper surface of a shallow 
cave (ca. $1 \mathrm{~m}$ high and $1 \mathrm{~m}$ deep) made by an overhanging rock ledge in Big Thompson Canyon (Colorado, USA).

\section{Dictyna calcarata}

Census Area No. $1(24 \mathrm{~cm} \times 24 \mathrm{~cm})$ and No. $2(54 \mathrm{~cm} \times 46 \mathrm{~cm})$ were web complexes on the external walls of buildings in Chapala (Jalisco, Mexico).

\section{RESULTS}

\section{POPULATION SIZE AND DENSITY}

Densities for $M$. trivittatus and $D$. calcarata were relatively similar (Table 1). Since the $M$. niveus aggregations were linear (onedimensional) it is problematic to compare densities in this species with the densities found in the other species. The webs of $M$. niveus in the census areas were oriented such that the shorter distance across each was vertical. The areas given in Table 1 were obtained by multiplying the length of the aggregations by $3 \mathrm{~cm}$, the mean widths of $M$. niveus webs found on buildings (Jackson, 1978a). M. gregalis tends to live in higher densities. The webs censused by Method No. 1 (Table 2) had a mean density of $0.5 \pm 0.66$ spiders per $\mathrm{cm}^{2}$ and $0.2 \pm 0.14$ per $\mathrm{cm}^{3}$.

Based on many hours spent in the culvert at E. Turkey Creek, it seems that the densities obtained in Census Nos. 1 and 2 for $M$. trivittatus were representative of the large complex in the culvert. Using the mean of the two densities for spiders $\left(14.23\right.$ per $\left.1000 \mathrm{~cm}^{2}\right)$, webs $\left(9.79\right.$ per $\left.1000 \mathrm{~cm}^{2}\right)$, and occupied webs $\left(8.79\right.$ per $\left.1000 \mathrm{~cm}^{2}\right)$ as estimates for the densities for the complex as a whole, this web complex contained 10,200 spiders, 7,700 webs, and 6,500 occupied webs. This was by far the largest web complex of this or any other species in this study.

Web units of $M$. trivittatus tend to be $5 \mathrm{~cm} \times 4 \mathrm{~cm}$; those of $D$. calcarata tend to be $3 \mathrm{~cm} \times 2 \mathrm{~cm}$; and webs of $M$. niveus on walls of buildings tend to be $4 \mathrm{~cm} \times 3 \mathrm{~cm}$ (Jackson, 1978a). In the culvert on E. Turkey Creek, the interstitial area between web units tended to be quite small, since the mean for nearest neighbor distance was not much greater than the diameter of web units (Table 1). In all other censused web complexes, web units tended to be 2 to 4 web unit diameters apart; and aggregated $M$. niveus webs tended to be 2 to 4 web diameters apart also. 


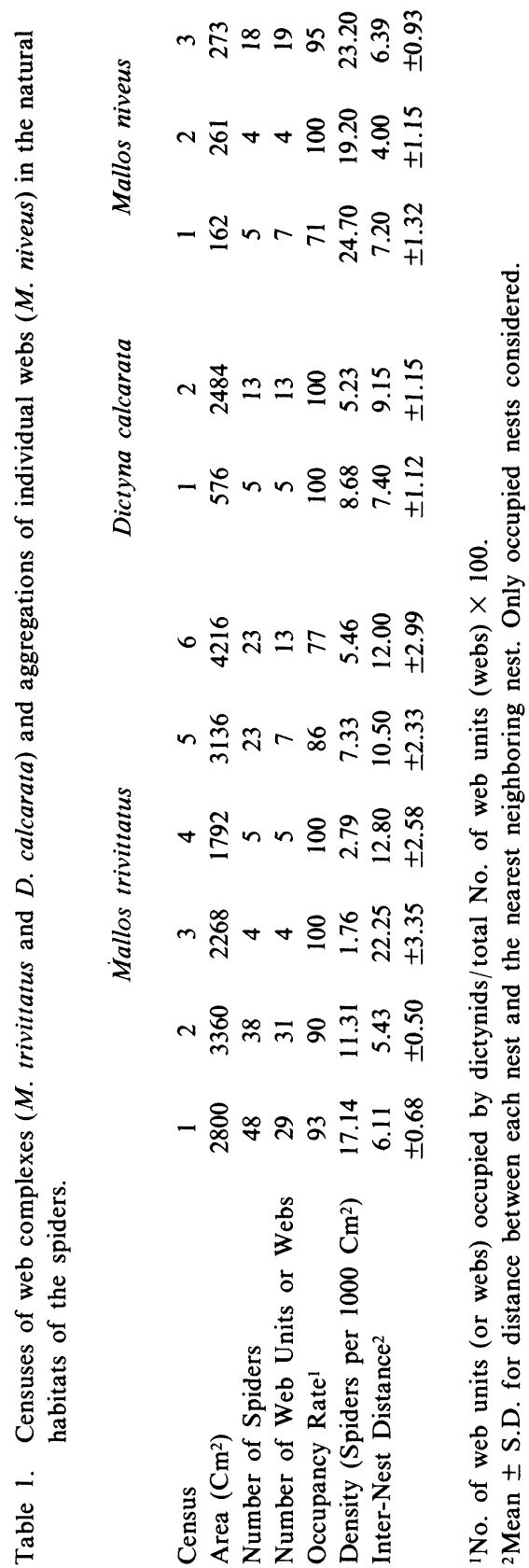


Some of the larger communal webs of $M$. gregalis in the laboratory had surface areas and volumes estimated to be as large as $1300 \mathrm{~cm}^{2}$ and $1500 \mathrm{~cm}^{3}$. If the densities in these large webs were comparable to those in smaller webs, they can be estimated to have contained 300 to 700 spiders. Based on the descriptions of Diguet (1909a, b) and Burgess (1976), $4 \mathrm{~m}^{2}$ will be used as an approximate estimate for the surface area of larger communal webs on trees in Mexico. If densities in nature are comparable to those in the laboratory then these very large webs may have contained as many as 20,000 spiders.

\section{WEB OCCUPANTS}

Solitary species, including $M$. niveus, usually occurred one spider per web (Jackson, 1978a), and this was true of all censused webs in the aggregations of $M$. niveus. However, each occupied web unit of the three communal, territorial species usually contained a set of several spiders. These could be almost any combination of females, males, and immatures of varied sizes (Table 3), except that web units were never shared by two adults of the same sex. In the only instances in which male-male or female-female pairs were seen together in the same web units, aggressive interactions took place, after which one individual departed. In contrast, large numbers of $M$. gregalis belonging to all sex/age classes shared the same communal webs without aggressive behavior or cannibalism.

\section{DISTRIBUTION OF WEB OCCUPANTS}

Large proportions of each sex/age class of $M$. trivittatus occupied the nests (Tables 3 and 4); but adult females were especially prone to be inside nests, and there was a preponderance of immatures in the interstitial web. These data were consistent with more casual observations of $M$. trivittatus in other locations and of the other communal, territorial species. During the day, $M$. niveus and other solitary species were most often, but not always, inside nests. All $M$. niveus in censuses were inside nests.

Many hours of casual observation in the laboratory gave the impression that adult males and immatures of $M$. gregalis were more prone to be on the outer surfaces of webs, and females were more prone to be in the interior. (Data related to this will be presented below.) 
Table 2. Data from complete disassembly of $19 \mathrm{M}$. gregalis webs or subunits of webs (census Method No. 1, see text). Area and volume are estimates, since borders of webs were irregular. Small immature: ca. $1 \mathrm{~mm}$ in body length (color: uniformly brown). Large immature: body length ca. $2 \mathrm{~mm}$ (gray markings present on body). Adult females: ca. $3 \mathrm{~mm}$. Adult males: ca. $3 \mathrm{~mm}$. Web class A: 3-D and lacking evidence of deserted areas. B: 3-D and containing conspicuous deserted areas. C: 2-D and lacking conspicuous deserted areas. D: 2-D (but not as flat as C) and containing conspicuous deserted areas. E: 3-D, small discrete web on irregular substrate. A-D: census areas were subunits of large webs, except for some of C that were discrete webs. 3-D: web occupies relatively much space in each of 3 dimensions. 2-D: web confined predominately to 2 dimensions ("flat"). "Deserted" areas: no longer occupied by $M$. gregalis, not substantially adhesive, and covered by fly carcasses and dust. Note: as population size increases, composition of population shifts toward decreasing percentages of females and increasing percentages of immatures. Kendall rank correlation (Sokal and Rohlf, 1969) for increasing percentages of small immatures with increasing population size $(\mathrm{P}<0.001)$.

\begin{tabular}{|c|c|c|c|c|c|c|c|c|}
\hline \multirow[b]{2}{*}{$\begin{array}{l}\text { Popu- } \\
\text { lation }\end{array}$} & \multirow[b]{2}{*}{$\begin{array}{l}\text { Area } \\
\left(\mathrm{cm}^{2}\right)\end{array}$} & \multirow[b]{2}{*}{$\begin{array}{l}\text { Volume } \\
\left(\mathrm{cm}^{3}\right)\end{array}$} & \multirow[b]{2}{*}{$\begin{array}{l}\text { Web } \\
\text { Class }\end{array}$} & \multirow[b]{2}{*}{$\begin{array}{l}\text { Popu- } \\
\text { lation } \\
\text { Size }\end{array}$} & \multicolumn{4}{|c|}{$\begin{array}{l}\text { Sex / Age Class Composition } \\
\text { (\%) of Population }\end{array}$} \\
\hline & & & & & $\begin{array}{l}\text { Adult } \\
\text { Female }\end{array}$ & $\begin{array}{l}\text { Adult } \\
\text { Male }\end{array}$ & $\begin{array}{l}\text { Large } \\
\text { Imma- } \\
\text { ture }\end{array}$ & $\begin{array}{c}\text { Small } \\
\text { Imma- } \\
\text { ture }\end{array}$ \\
\hline 1 & 144 & 144 & $\mathrm{C}$ & 5 & 60.0 & 0.0 & 20.0 & 20.0 \\
\hline 2 & 144 & 144 & $\mathrm{C}$ & 7 & 71.4 & 0.0 & 14.2 & 14.2 \\
\hline 3 & 105 & 300 & $\mathrm{C}$ & 9 & 0.0 & 11.1 & 44.4 & 44.4 \\
\hline 4 & 150 & 300 & $\mathrm{D}$ & 10 & 90.0 & 10.0 & 0.0 & 0.0 \\
\hline 5 & 144 & 144 & $\mathrm{D}$ & 10 & 30.0 & 0.0 & 10.0 & 60.0 \\
\hline 6 & 75 & 150 & B & 11 & 27.3 & 0.0 & 27.3 & 45.4 \\
\hline 7 & 70 & 150 & B & 21 & 19.0 & 0.0 & 19.0 & 61.0 \\
\hline 8 & 70 & 350 & A & 23 & 65.2 & 17.4 & 17.4 & 0.0 \\
\hline 9 & 150 & 150 & B & 25 & 4.0 & 4.0 & 8.0 & 84.0 \\
\hline 10 & 70 & 350 & A & 27 & 48.2 & 18.5 & 7.4 & 25.9 \\
\hline 11 & 144 & 144 & $\mathrm{C}$ & 31 & 12.9 & 0.0 & 0.0 & 87.0 \\
\hline 12 & 70 & 350 & $\mathrm{E}$ & 34 & 11.7 & 5.8 & 32.3 & 50.0 \\
\hline 13 & 64 & 320 & B & 40 & 27.5 & 0.0 & 40.0 & 32.5 \\
\hline 14 & 150 & 600 & A & 47 & 23.4 & 6.3 & 21.3 & 48.9 \\
\hline 15 & 155 & 155 & D & 53 & 32.1 & 0.0 & 20.7 & 47.2 \\
\hline 16 & 100 & 300 & A & 74 & 17.5 & 1.3 & 22.2 & 55.4 \\
\hline 17 & 400 & 800 & A & 82 & 9.7 & 2.4 & 7.3 & 80.4 \\
\hline 18 & 45 & 225 & A & 114 & 7.0 & 0.0 & 12.3 & 80.4 \\
\hline 19 & 150 & 600 & A & 288 & 9.3 & 2.0 & 9.7 & 78.8 \\
\hline
\end{tabular}


SEX/AGE CLASS RATIOS

Based on the spiders in the two censuses in the culvert at E. Turkey Creek, this large web complex was estimated to have had a population consisting of $27 \%$ adult females, $9 \%$ adult males, and $64 \%$ immatures. The adult sex ratio (Male:Female) was approximately 1:3. Based on the censuses at Chapala, populations of $D$. calcarata in web complexes on buildings were composed of $14 \%$ adult females, $5 \%$ adult males, and $81 \%$ immatures; and the adult sex ratio was $1: 3$, as for $M$. trivittatus. No males were found in the censuses of $M$. niveus. Generally only small numbers of males of the solitary species were found, and these were predominantly ones in webs with females (Jackson, 1977b).

Based on the 19 censuses of $M$. gregalis by Method No. 1 (disassembly), population composition was $29.8 \pm 25.49 \%$ adult females, $4.1 \pm 5.97 \%$ adult males, $17.6 \pm 12.17 \%$ large immatures, and $48.2 \pm 27.41 \%$ small immatures. Immatures comprised a greater proportion of the spiders in webs with large population size (Table 2). The average adult sex ratio was approximately 1:7. For the 33 transect censuses (Method No. 2), population composition was 12.3 $\pm 7.44 \%$ adult females, $3.0 \pm 3.85 \%$ adult males, $38.0 \pm 12.96 \%$ large immatures, and $46.2 \pm 13.11 \%$ small immatures (adult sex ratio, ca. $1: 4)$, with a total of $16.8 \pm 2.34$ spiders occurring in each census. The three sections of the web were comparable.

\section{Discussion}

\section{AGGREGATION SIZE AND DENSITY -}

EVOLUTIONARY CONSIDERATIONS

The occurrence in certain areas of very large populations of some species, especially $M$. gregalis and $M$. trivittatus, and the great densities of spiders within these populations contrast markedly with the majority of Dictyna and Mallos species. Most species are solitary, with individuals living in relatively widely spaced individual webs on stems and leaves of vegetation (Jackson, 1978a); and although density censuses were not carried out for these, our impression is that an area of 50 to $100 \mathrm{~m}^{2}$ in a population of a solitary species would usually contain fewer than a dozen individuals. In contrast, the largest web complex of $M$. trivittatus occupied approximately this much space and contained more than 10,000 individuals. 
A related comparison can be made by looking at the amount of web area or volume per individual spider for different species. There is a trend toward decreasing web surface per spider as one goes from solitary to communal species. Individual webs of solitary species tend to have a surface area of $35 \mathrm{~cm}^{2}$ (Jackson, 1978a). Since each web unit in web complexes of communal, territorial species tends to contain 2 or 3 spiders (Table 3), and since web units tend to have a surface area of 4 to $21 \mathrm{~cm}^{2}$ (Jackson, 1978a), there tends to be 1 to 7 $\mathrm{cm}^{2}$ of surface area per spider in these species. In the laboratory, in communal webs of $M$. gregalis, there tends to be a surface area of $2.1 \mathrm{~cm}^{2}$ and a volume of $6.4 \mathrm{~cm}^{3}$ of web per spider. (Volume was not calculated for other species since their webs tended to be largely 2 dimensional; Jackson, 1978a.)

The influence of prey availability on these trends deserves attention. Diptera of the same approximate size relative to the spider seem to predominate in the diet of species of Dictyna and Mallos

Table 3. Percentages of web units (in web complexes) occupied by different sex/ age class combinations. Data based on nests alone ( $M$. trivittatus) given in parentheses. More than one immature sometimes occurred together in same web unit. More than one adult of same sex never occurred together. N: No. of web units sampled, including ones in Table 1 plus others (ones not occupied by dictynids excluded).

\begin{tabular}{lccc} 
& M. trivittatus & D. calcarata & D. albopilosa \\
& $33.33(34.15)$ & 30.30 & 39.13 \\
Females $^{1}$ & $7.58(4.07)$ & 24.24 & 21.74 \\
Males $^{1}$ & $84.09(75.61)$ & 77.24 & 65.22 \\
Immatures $^{1}$ & $14.39(20.33)$ & 7.58 & 21.74 \\
Female Only $_{\text {Male Only }}$ & $0.76(1.63)$ & 9.09 & 8.70 \\
Immatures Only & $61.36(61.79)$ & 56.06 & 47.83 \\
Female plus Immatures Only & $16.67(13.82)$ & 12.12 & 8.70 \\
Female plus Male Only & $0.76(0.00)$ & 9.09 & 8.70 \\
Male plus Immatures Only & $4.55(2.44)$ & 7.58 & 8.70 \\
Female, Male, and Immatures & $1.52(0.00)$ & 1.52 & 0.00 \\
No. of Spiders per Web Unit ${ }^{2}$ & $3.1 \pm 4.83(20)$ & $1.6 \pm 0.91(4)^{3}$ & $1.3 \pm 0.47(2)^{3}$ \\
N & $132(123)$ & 66 & 23 \\
\multicolumn{4}{l}{ Regardless of other sex/age classes present. } \\
${ }^{2}$ Mean \pm S.D. (maximum). \\
${ }^{3}$ Larger maxima were seen during more casual observations.
\end{tabular}


(Jackson, 1977a). Thus large prey populations would seem necessary to support some of the larger aggregations of dictynids. Diguet (1909a, b, 1915) and Burgess (pers. comm.) noted numerous adult Diptera in the vicinity of $M$. gregalis webs in Mexico during the rainy season. Studies are needed to determine whether Diptera populations are larger and/or more predictable in habitats containing communal webs of $M$. gregalis compared to neighboring areas without communal webs. Great numbers of Diptera were noted in the metal culvert in Arizona that contained the enormous web complex of $M$. trivittatus. Another consideration in this case is that flies entering the culvert may be especially vulnerable to capture, since inside the culvert they were almost completely surrounded by web. Great masses of nematocerous flies were active in the vicinity of web complexes of $D$. calcarata in Chapala, emerging from nearby Lake Chapala in the late afternoon and early evening. Diptera were also numerous in the vicinity of web complexes of D. albopilosa at San Anton Falls. In general, wherever there were web complexes, there were also numerous Diptera.

However, the question of why some species live in large, dense populations, while others do not, cannot be answered simply on the basis of prey densities in the habitats of different species. Riechert and Tracy (1975) have shown relationships between density within spider populations and prey availability. However, they found prey availability to depend not only on the absolute abundance of prey but also on factors that influence how the spider experiences prey abundance, especially its thermal relations with its environment.

Another consideration is that species of Dictyna and Mallos with differing aggregating tendencies may occur side-by-side in the same habitats (Jackson, 1978a). For example, M. niveus were found in individual webs on the same trees with web complexes of $M$. trivittatus in the Chiracahua Mountains. It would seem that dictynid species that routinely occur in aggregated states (communal, territorial and communal, non-territorial) and those that generally live more widely dispersed (solitary) are somehow adapted to exploit different sets of resources, but we have no clear insights at this time concerning what these different resources might be.

The adaptive advantages and disadvantages for animals related to living in groups have been subjects of considerable interest in recent years (see Wilson, 1975). For a review of ideas concerning spiders, 
Table 4. Distribution of sex/age classes of $M$. trivittatus within web complexes. Based on occupied web units. No. of spiders: means \pm S.D. Females, Immatures, Males: percentages of the total found for each that were in each part of the web complex. Total: Number of spiders - mean \pm S.D. for spiders - per web unit (spiders in interstitial web included with nearest web unit); Females, Immatures, Males - percentage of total number of spiders belonging to each sex/age class.

$\begin{array}{lcccc} & \begin{array}{c}\text { Number of } \\ \text { Spiders }\end{array} & \text { Females } & \text { Males } & \text { Immatures } \\ & 1.5 \pm 1.88 & 93.33 & 50.00 & 52.49 \\ \text { Inside Nest } & & & & \\ \text { Inside Mesh } & 0.1 \pm 0.47 & 6.67 & 30.00 & 4.32 \\ \quad \text { Less than 2 cm from Nest } & 0.1 \pm 0.38 & 0.00 & 20.00 & 5.98 \\ \quad \text { More than 2 cm from Nest } & 0.9 \pm 2.19 & 0.00 & 0.00 & 37.21 \\ \text { Inside Interstitial Web } & 3.1 \pm 4.83 & 12.64 & 2.81 & 84.55 \\ \text { Total } & & & \end{array}$

see Buskirk (1975) and Lubin (1974). With the dictynids, we need to compare the varied species with respect to the importance of each potential advantage and disadvantage, given the nature of the resources each species exploits.

\section{PHENOLOGY}

Most Dictyna and Mallos probably have an annual life cycle in nature, with adult females and males present during spring, summer and/or fall (Chamberlin and Gertsch, 1958). The mating season for Mallos species generally seems to be later than that of Dictyna species, although the season for some species may last many months. Since both adult males and adult females were found, evidently each census was carried out during the mating season of the species involved, although not necessarily during the peak of the season for all species. No doubt, if censuses had been undertaken at different times of the year, different ratios of each sex/age class would have been found for each species.

Seasonal changes in the ratios of the different sex/age classes in laboratory populations of $M$. gregalis apparently occur, although data have not been collected. Each sex/age class was found throughout the year, but males were less numerous in winter than in other seasons. The differences in adult sex ratios in the two types of censuses of $M$. gregalis may be a reflection of the tendency, noted during casual observation, for females to predominate in the interior of webs, with males predominating on the exterior. How- 
ever, another factor that must be considered is that the two types of censuses were made at different times of the year, and differences may be influenced by phenology.

\section{CAUSES OF DISTRIBUTION PATTERNS WITHIN WEBS}

In all species, eggs tend to be oviposited in the vicinity of the nests, and the tendency for females to be found in nests is probably at least partly related to this. Also, nests may be optimal resting sites with respect to protection from predators and parasites (Jackson, 1978a). If obtaining space within a nest is accompanied by aggressive behavior, which seems likely in the communal, territorial species, then females may have an advantage related to their larger size. Females in each species have the largest body size of any sex/age class. Compared to males, females may be more sedentary; and a stronger tendency to occupy nests may be related to this. This might also apply to comparison of females with immatures if the immatures are the dispersal phase in the life histories of these species. Also, by virtue of their smaller size, young immatures may be safer from predation on the mesh or interstitial web than females, since they might take refuge under strands of silk, particles of debris, etc., which are too small to be effective for females. As a result, there might be lesser selection pressure against immatures that remain outside nests compared to larger females that remain outside nests.

Since females seem to be prone to be in the interior of webs of $M$. gregalis, we might expect males to spend considerable time searching for and courting females in the interior of webs. Instead, more males seem to be on the exterior surfaces of the webs. In M. gregalis, unlike $M$. trivittatus and D. calcarata, the presence of females and silk spun by females are not releasers of courtship behavior. Instead, males seem to have an advertising routine, as part of their daily activity pattern, in which they perform behavior referred to as "pluck-walking." Females seem to indicate their receptivity to pluck-walking males by failing to run away (Jackson, 1978b). We do not know the factors that determine female receptivity, but perhaps receptive females are more likely to be on the outer surfaces of webs. For example, females might be unreceptive near the time of oviposition, and oviposition takes place in the interior of the web. Although the difficulty of observing behavior of spiders in the interior of webs should be kept in mind, it is of interest that the 
majority of observed instances of pluck-walking involved males on the surfaces of webs.

We have no information at this time concerning how new communal webs are formed by $M$. gregalis. One possibility is that new webs are founded by single adult females or by groups of several adult females. In the laboratory web censuses (method 1), the webs with fewer spiders (predominantly adult females) may have been ones that were newly founded. Those with more spiders and a greater proportion of smaller immatures may have been older webs in a period of rapid growth. Further study, especially in the natural habitats of these spiders, is necessary. Information is also lacking on the formation of web complexes by M.trivittatus and $D$. calcarata.

\section{CAUSES OF SKEWED SEX RATIOS}

The causes of the relative rarity of males in all species investigated are unknown. We do not know the sex ratios at hatching. If maternal investment in progeny of the two sexes is equal, we would expect a 1:1 ratio (Fisher, 1930; but see Hamilton, 1967; Trivers and Willard, 1973). There are a number of factors that might skew the adult ratio in favor of females even if the ratio at hatching is 1:1. Earlier studies (Jackson, 1978b) suggested that adult males of solitary and communal, territorial species are relatively nomadic, expending considerable time and energy wandering about searching for females. As a result, a sizeable proportion of the males in populations of these species might not be found in censuses of webs. Also, the nomadic character of males might subject them to earlier mortality from predation, starvation, and other factors. Shorter male longevity would skew the adult sex ratio in favor of females. However, mortality factors such as predation would seem less important for $M$. gregalis populations in the laboratory; yet the sex ratio was skewed in favor of females here also, suggesting that mortality factors of a more intrinsic nature might be involved. Females of each investigated species oviposited several batches of eggs over a period of time. In contrast to females, males may be adapted to a lifestyle that emphasizes courtship, mating, and searching for females, in conjunction with greater vagility and smaller size, at the expense of maintenance functions that would serve to prolong survival. 


\section{ACKNOWLEDGEMENTS}

For comments on the manuscript, we thank P. N. Witt, and M. C. Vick. Special thanks go to W. J. Gertsch for his assistance in the identification of spiders. C. E. Griswold, P. S. Jackson, and V. D. Roth are gratefully acknowledged for assistance in the field. The assistance of the Southwestern Research Station of the American Museum of Natural History is gratefully acknowledged. This work was supported in part by the North Carolina Division of Mental Health Services, Research Section and by N.S.F. grant number BMS 75-09915 to P. N. Witt.

\section{SUMMARY}

Three types of social organization and three corresponding types of webs occur in the Dictynidae: solitary (individual webs); communal, territorial (web complexes); communal, non-territorial (communal webs). Solitary (M. niveus) and communal, territorial (M. trivattatus, D. calcarata, and D. albopilosa) species were censused in nature; for $M$. gregalis (communal, non-territorial), free-living populations in communal webs in the laboratory were censused. Web surface area per spider decreases as one goes from solitary (ca. $35 \mathrm{~cm}^{2}$ ) to communal, territorial (ca. $10 \mathrm{~cm}^{2}$ ) to communal, non-territorial (ca. $2 \mathrm{~cm}^{2}$ ) species. Very large populations may occur on single web structures of communal species (estimates of maxima: M. trivittatus, 10,000 spiders; M. gregalis, $20,000)$. There is a tendency for adult females to occupy nests and the interior of webs, with males and immatures occupying the exterior and the interstitial areas. Sex ratios (male:female) are skewed in favor of females (M. gregalis 1:7; communal, territorial species, 1:3; males of solitary species are infrequently found).

REFERENCES

BURGESS, J. W.

1976. Social spiders. Sci. Amer. 234: 100-106.

1978. Social behaviour in group-living spider species. Symp. Zool. Soc. London (In Press).

BUSKIRK, R. E.

1975. Coloniality, activity patterns and feeding in a tropical orb-weaving spider. Ecology 56: 1314-1328. 
Chamberlin, R. V. and W. J. Gertsch.

1958. The spider family Dictynidae in America north of Mexico. Bull. Amer. Mus. Nat. Hist. 116: 1-152.

DigueT, L.

1909a. Sur l'Araignée mosquero. C.R. Acad. Sci. Paris 148: 735-736.

1909b. Le mosquero. Nid d'Araignée employé dans certaines régions du Mexique comme piège à mouches. Bull. Soc. Acclim. France 56: 368-375.

1915. Nouvelles observations sur le mosquero ou nid d'Araignées sociales employé comme piège à mouches dans certaines localités du Mexique. Bull. Soc. Acclim. France 62: 240-249.

Hamilton, W. D.

1967. Extraordinary sex ratios. Science (N.Y.) 156: 477-488.

FISHER, R. A.

1930. The Genetical Theory of Natural Selection. Clarendon, Oxford.

JACKSON, R. R.

1977a. Comparative studies of Dictyna and Mallos (Araneae:Dictynidae): III. Prey and feeding behavior. Psyche 83: 267-280.

1977b. Web sharing by males and females of dictynid spiders. Bull. Brit. Arach. Soc. 4: $109-112$.

1978a. Comparative studies of Dictyna and Mallos (Araneae,Dictynidae): I. Social organization and web characteristics. Rev. Arach. 1: 133-164.

1978b. Male mating strategies of dictynid spiders with differing types of social organization. Symp. Zool. Soc. London (In Press).

KRAFFT, B.

1970. Contribution à la biologie et à l'Ethologie d'Agelena consociata Denis (Araignée sociale de Gabon). Première Partie. Biol. Gabon. 6: 197-301.

Kullmann, E.

1972. Evolution of social behavior in spiders (Araneae; Eresidae and Theridiidae). Amer. Zool. 12: 419-426).

LUBIN, Y. D.

1974. Adaptive advantages and the evolution of colony formation in Cyrtophora (Araneae:Araneidae). Zool. J. Linn. Soc. 54: 321-339.

RIEChERT, S. E. AND C. R. TRACY.

1975. Thermal balance and prey availability: bases for a model relating website characteristics to spider reproductive success. Ecology 56: 265-284.

SheAR, W. A.

1970. The evolution of social phenomena in spiders. Bull. Brit. Arach. Soc. 1: 65-76.

SOKAL, R. R. AND F. J. RoHLF.

1969. Biometry. Freeman, San Francisco.

TRIVERS, R. L. AND D. E. WILlard.

1973. Natural selection of parental ability to vary sex ratio of offspring. Science (N.Y.) 179: 90-92.

WILSON, E. O.

1975. Sociobiology. Belknap, Cambridge. 

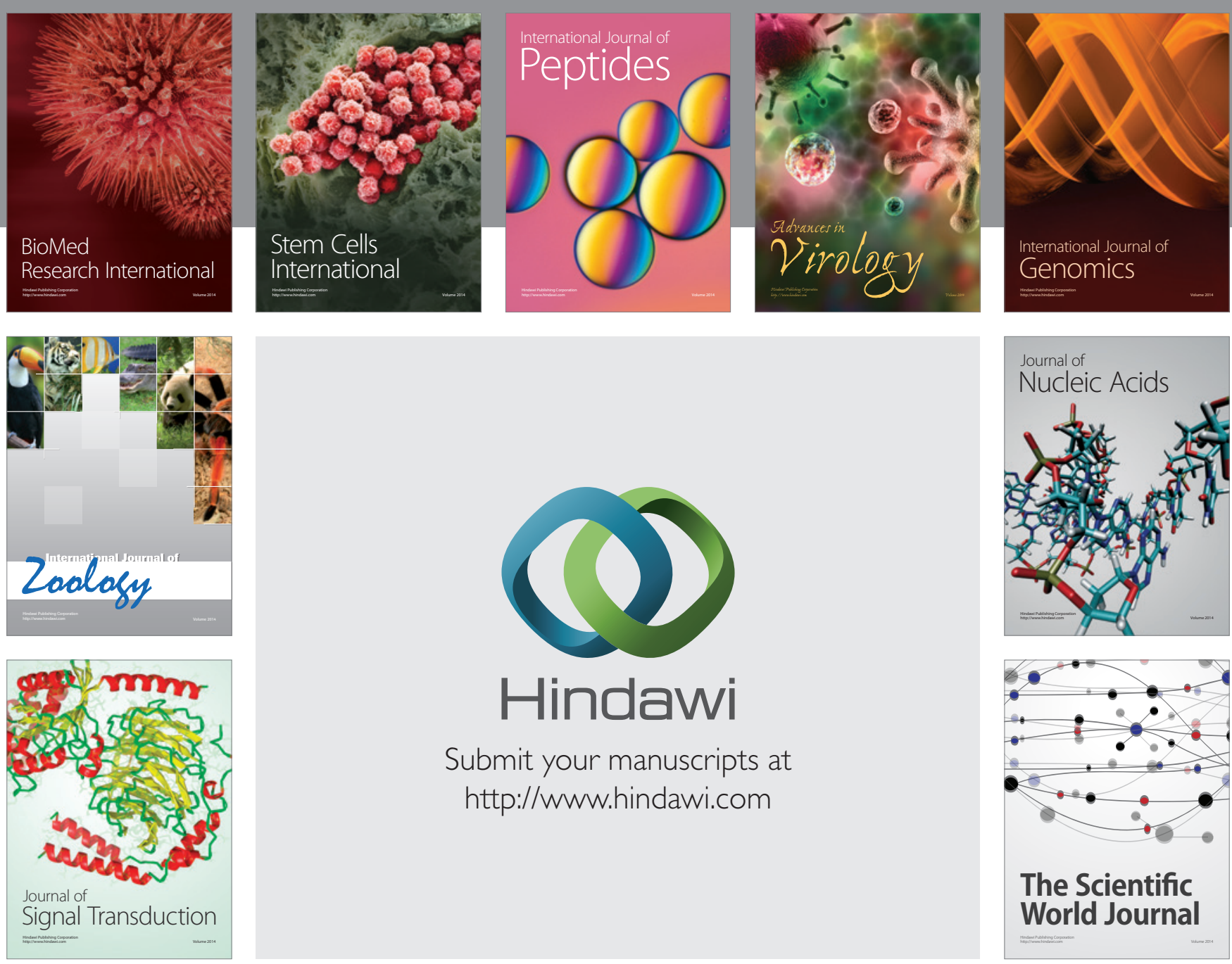

Submit your manuscripts at

http://www.hindawi.com
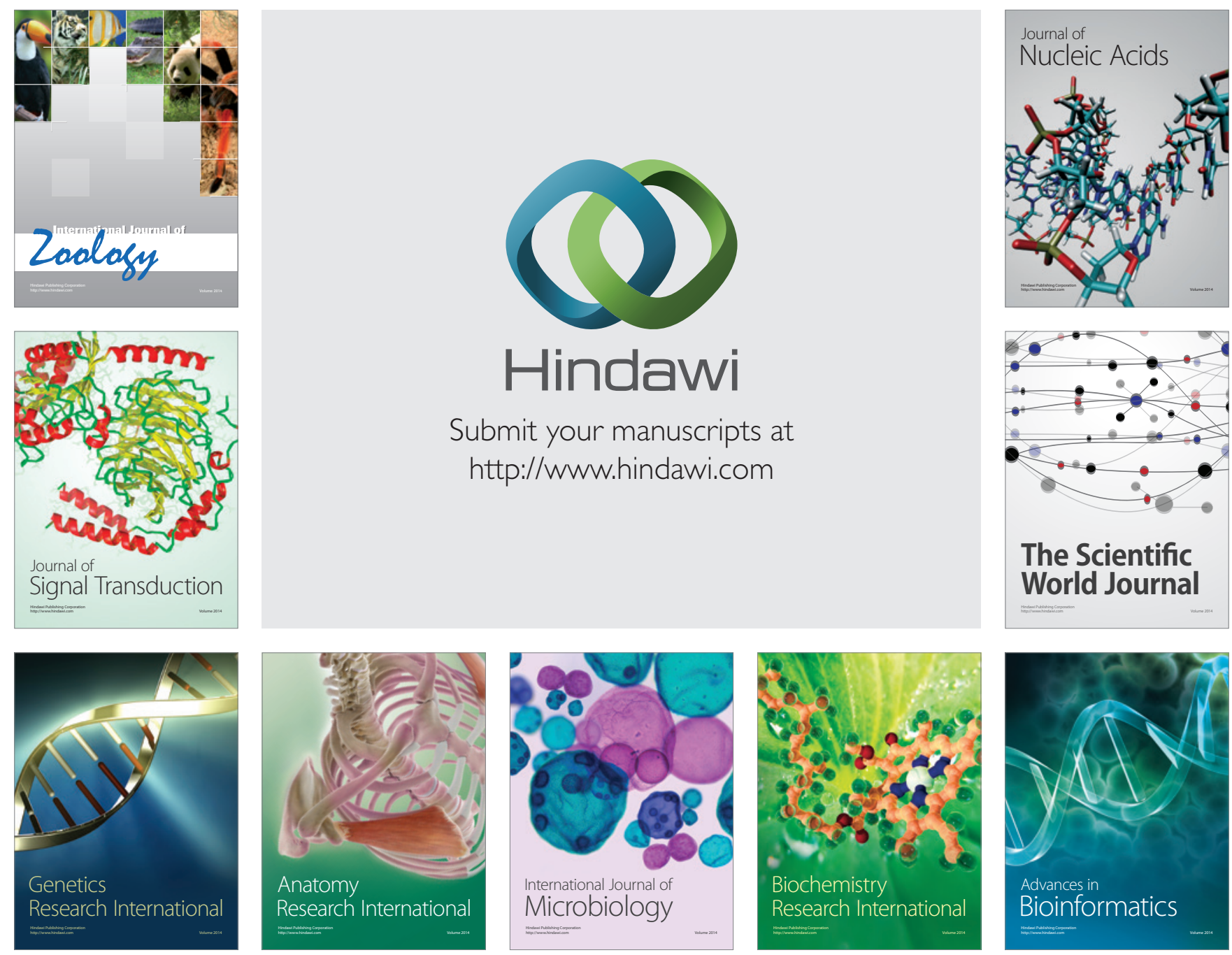

The Scientific World Journal
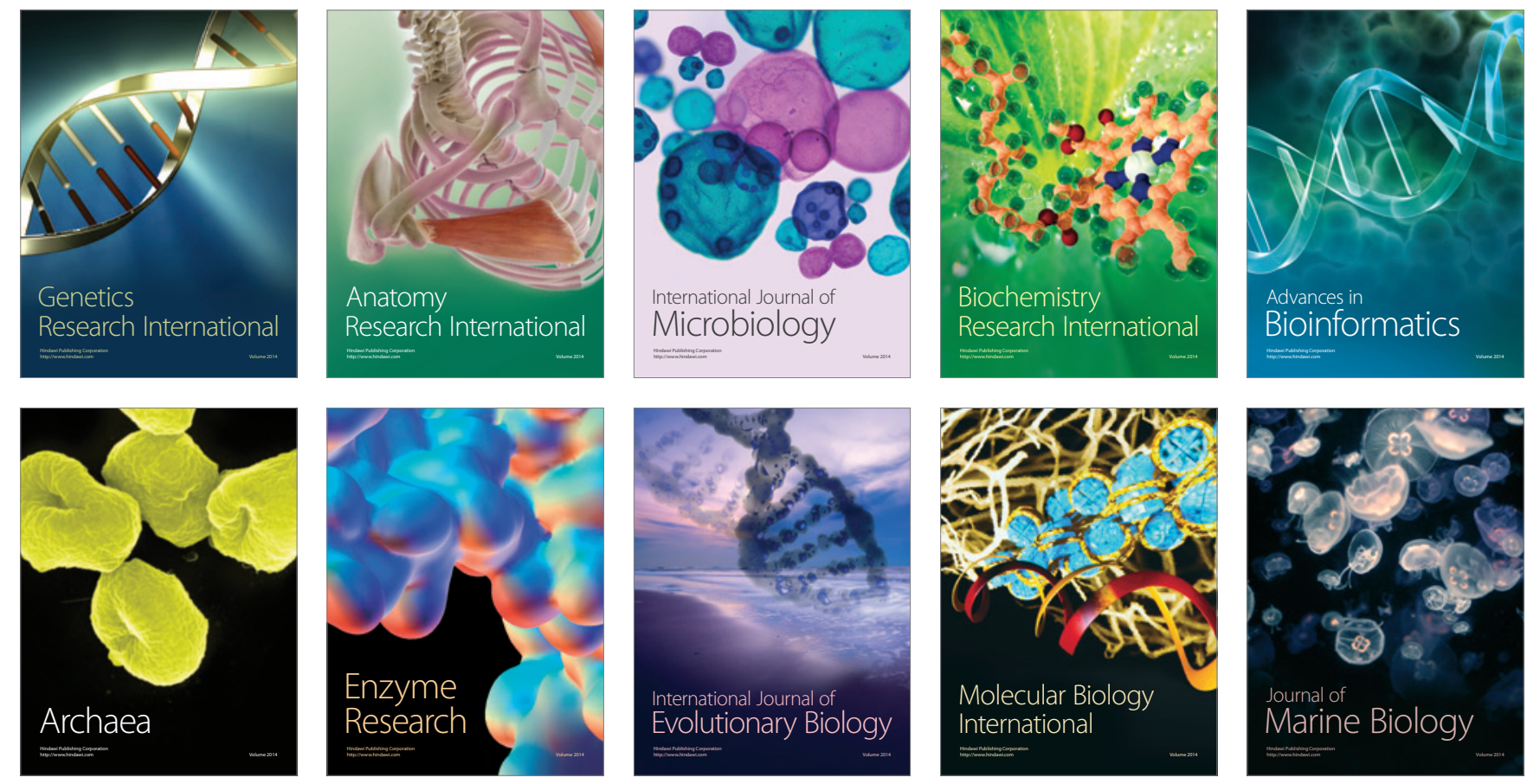